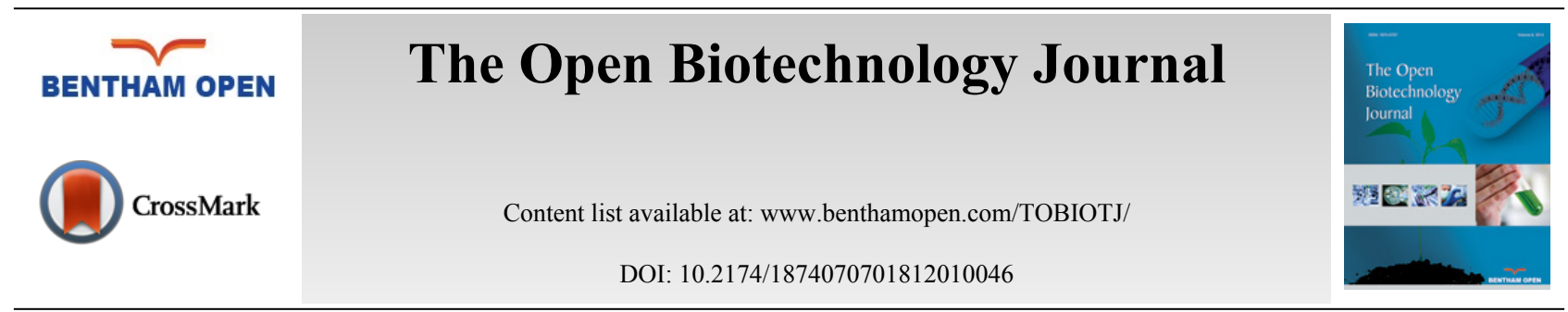

RESEARCH ARTICLE

\title{
Detection and Molecular Characterization of Vibrio Parahaemolyticus in Shrimp Samples
}

\author{
Daryoush Asgarpoor ${ }^{1,2}$, Fakhri Haghi ${ }^{2}$ and Habib Zeighami ${ }^{2, *}$ \\ ${ }^{\text {I} S t u d e n t ~ R e s e a r c h ~ C e n t e r, ~ Z a n j a n ~ U n i v e r s i t y ~ o f ~ M e d i c a l ~ S c i e n c e s, ~ Z a n j a n, ~ I r a n ~}$ \\ ${ }^{2}$ Department of Microbiology, Zanjan University of Medical Sciences, Zanjan, Iran
}

Received: November 25, 2017

Revised: January 30, 2018

Accepted: March 13, 2018

\begin{abstract}
:
\section{Background:}

Food safety has emerged as an important global issue with international trade and public health implications. Bacterial pathogens asVibrio parahaemolyticus recognized as an important cause of foodborne diseases related to the consumption of raw, undercooked or mishandled seafood worldwide.
\end{abstract}

\section{Methods:}

A total of 70 individual wild shrimp samples were collected from shrimp retail outlets in Zanjan, Iran and investigated for the presence of potentially pathogenic strains of $V$. parahaemolyticus. The shrimp samples were immediately homogenized and cultured on TCBS agarand subjected to confirmatory biochemical tests. Polymerase Chain Reaction (PCR) was performed for detection of total and pathogenic $V$. parahaemolyticus by amplification of $v p-t o x R, t d h$ and trh genes.

\section{Results:}

The conventional method indicated that $16(22.8 \%)$ of samples were positive for $V$. parahaemolyticus. However, PCR verified that only $12(17.1 \%)$ shrimp samples were positive for $V$. parahaemolyticus. Of the 70 shrimp samples in our study, only $2(2.8 \%) t d h$ and $1(1.4 \%)$ trh positive strains were identified.

\section{Conclusion:}

Detection of $t d h$ and/ or trh positive V. parahaemolyticus in shrimp marketed in Zanjan, Iran shows a probable risk for public health. Therefore, the reliable molecular methods for monitoring of potentially pathogenic $V$. parahaemolyticus are strongly recommended for the routine seafood examination.

Keywords: Vibrio parahaemolyticus, Shrimp, PCR, Molecular characterization, $v p-t o x R, t d h$, trh genes.

\section{INTRODUCTION}

Vibrio parahaemolyticus is a halophilic marine bacterium and some strains can cause gastroenteritis in humans through the consumption of raw, undercooked or mishandled contaminated seafood [1,2]. Although the gastroenteritis caused by $V$. parahaemolyticus is often self-limited and characterized by diarrhea, headache, vomiting, nausea, abdominal cramps and low fever, the infection may cause septicemia, a life-threatening infection, in immunocompromized patients [3 - 5]. The pathogenic strains of $V$. parahaemolyticus are characterized by the production of Thermo stable Direct Hemolysin (TDH) and/or TDH-Related Hemolys in (TRH) that can lyse the red blood cells on Wagatsuma blood agar (referred to as the Kanagawa phenomenon) and encoded by $t d h$ and trh genes,

\footnotetext{
* Address correspondence to this author at the Department of Microbiology, Zanjan University of Medical Sciences, Zanjan, Iran, Tel: +982433140296, Fax: +982433449553; E-mail: zeighami@zums.ac.ir
} 
respectively [3, 6]. The ubiquitous nature of Vibrio spp. in marine and estuarine environments makes it impossible to obtain seafood completely free of these species. It has been implicated in several outbreaks of seafood poisoning worldwide [6, 7]. Previous epide miological studies showed that $V$. parahaemolyticus is an important cause of foodborne disease in Asia, South America and the United States. The V. parahaemolyticus is frequently isolated from shellfish including oysters, clams, mussels, lobsters, crabs, shrimps and cockles, which provide an excellent substrate for the growth of these micro organisms in the aquatic habitats [8 - 13]. Many studies have been carried out on shellfish and findings concerning the distribution of $V$. parahaemolyticus in oysters and mussels are well documented. However, few data are available forcrustaceans, despite the popularity of crabs and shrimps and their rising consumption worldwide [14]. Shrimp is one of the most important fishery products, and shrimp farming is an important economy characteristic of Iran [13]. The frequency of pathogenic $V$. parahaemolyticus infrozen ready-to-eat shrimps for human consumption was recently studied, and 7 to $8 \%$ of samples tested positive for $t d h$ or $t r h$ virulence genes in countries such as Malaysia. Therefore, these shrimps might have the potential to cause $V$. parahaemolyticus-associated infections if consumed without further processing [14].

In recent years, $V$. parahaemolyticus has been recognized as the causative agent of $50-70 \%$ of all cases of gastroenteritis associated with consumption of seafood [5].

There are different methods for detection of $V$. parahaemolyticus in seafood samples. The most-probable-number (MPN) method is used for enumeration of $V$. parahaemolyticus from food and water, but this method is cumbersome and the recovery of the organism is low [15].The culture-based approaches and PCR technique which is faster, easier and more sensitive can be used for identification of $V$. parahaemolyticus in seafood samples [10]. The $V$. parahaemolyticus strains possess a regulatory gene, tox $R$, which is present in all strains irrespective of their ability to produce $t d h$ and/or $t r h$. Therefore, the PCR targeted to the toxR gene can be used as a method for identification at the species level [16].

The objective of this study was to determine the frequency of pathogenic $V$. parahaemolyticus in wild shrimp samples using the culture and PCR methods based on detection of $t d h$ and trh virulence genes in Zanan, Iran.

\section{MATERIALS AND METHODS}

\subsection{Sampling}

From March to June 2015, a total of 70 individual wild shrimp samples were collected from shrimp retail outlets in Zanjan, Iran. Shrimp samples were packed into a clean polyethylene bag then marked and transported to the laboratory of food microbiology in a cooler with ice packs for analysis within $1 \mathrm{~h}$.

\subsection{Reference Strain}

The $V$. parahaemolyticus ATCC 17802 waskindly obtained from the Pasteur Institute of Iran and was grown on Thiosulphate Citrate Bile Salt Sucrose (TCBS) Agar (MERCK, Darmstadt, Germany).

\subsection{Isolation and Identification of $V$. Parahaemolyticus}

The isolation and biochemical identification of $V$. parahaemolyticus were carried out as recommended in the FDA's Bacteriological Analytical Manual. Twenty five gram of the samples were homogenized for $60 \mathrm{~s}$ in a stomacher (Heidolph, Schwabach, Germany) with $225 \mathrm{~mL}$ of alkaline peptone water (APW) containing $3 \% \mathrm{NaCl}$ and then incubated for enrichment at $37^{\circ} \mathrm{C}$ for $24 \mathrm{~h}$. After primary enrichment, a loopful (without shaking the flask) from each of the enriched homogenate was streaked onto the surface of Thiosulfate Citrate Bile Sucrose (TCBS) agar plates (MERCK, Darmstadt, Germany)and incubated at $37^{\circ} \mathrm{C}$ for 24 h.On TCBS plates, sucrose negative colonies (green or blue-greencolonies with $2-3 \mathrm{~mm}$ in diameter), were picked up and inoculated into tryptonesoya broth with $3 \% \mathrm{NaCl}$, incubated at $37^{\circ} \mathrm{C}$ for $24 \mathrm{~h}$, then purified onto nutrient agar slants with $3 \% \mathrm{NaCl}$ and subjected for confirmatory biochemical tests using different media contained 2.5\% NaCl. Every single colony was screened for Gram staining, motility, oxidase and urease activity, $\mathrm{NaCl}$ requirement, citrate utilization, triple sugar iron agar, arginine dehydrolase, lysine and ornithine decarboxylase, $\mathrm{O} / 129$ sensitivity, vogese proskauer, indole and acid production from lactose, arabinose, cellobiose, mannitol and mannose.

\subsection{Genomic DNA Extraction}

A colony of $V$. parahaemolyticus (one colony per sample) was picked from nutrient agar and inoculated into $5 \mathrm{ml}$ of 
LB (Luria Bertani Broth, Merck) until the exponential phase with 2 McFarland turbidity with shaking at $120 \mathrm{rpm}$ at $37^{\circ} \mathrm{C}$. One $\mathrm{ml}$ from an overnight culture in LB was spun at $8,000 \mathrm{rpm}$ for $5 \mathrm{~min}$. The supernatant was discarded and the cell pellet was resuspended in $200 \mu \mathrm{L}$ sterile deionized water and boiled at $100^{\circ} \mathrm{C}$ for $10 \mathrm{~min}$. The tube was immediately placed in ice for $5 \mathrm{~min}$; then the cell lysate was centrifuged at 13000 r.p.m. for 3 min to pellet the cell debris and the clear supernatant was transferred to a new tube. A $5 \mu 1$ aliquot of supernatant was used for PCR.

\subsection{Molecular Confirmation of $V$. Parahaemolyticus Isolates}

Confirmation of presumptive $V$. parahaemolyticus isolates was performed using PCR targeting the $v p-t o x R$ gene with the following primers and amplicon size $368 \mathrm{bp}$ : toxR-F:5'-GTCTTCTGACGCAATCGTTG-3' and toxR-R:5'-ATACGAGTGGTTGCTGTCATG-3' [2]. A specific primer pairs were also used for detection of $t d h$ and $t r h$ virulence genes in tox $R$ positive strains with the following sequences: $t d h-F: 5^{\prime}-$ CCACTACCACTCTCATATGC-3' , $t d h-R: 5$ '-GGTACTAAATGGCTGACATC-3' with amplicon size $251 \mathrm{bp}$ and $t r h-F: 5$ 'GGCTCAAAATGGTTAAGCG $-3^{\prime}$ and $t r h-R: 5^{\prime}-$ CATTTCCGCTCTCATATGC-3' with amplicon size $250 \mathrm{bp}$ [10]. Single PCR was performed using Dream Taq PCR Master Mix (Thermo Fisher Scientific), which contains Taq polymerase, dNTPs, $\mathrm{MgCl}_{2}$ and the appropriate buffer. Each PCR tube contained $25 \mu 1$ reaction mixture composed of $12.5 \mu 1$ of the master mix, $2.5 \mu 1$ of each forward and reverse primer solution (in a final concentration of $200 \mathrm{nM}$ ), $5 \mu$ l of DNA and nuclease-free water to complete the final volume. PCR was performed using the Gene Atlas 322 system (ASTEC) with the same cycling conditions for $t o x R$, $t d h$ and $t r h$ genes. Amplification involved an initial Denaturation at $94^{\circ} \mathrm{C}, 5$ min followed by 30 cycles of denaturation $\left(94^{\circ} \mathrm{C}, 1 \mathrm{~min}\right)$, annealing $\left(57^{\circ} \mathrm{C}, 1.5 \mathrm{~min}\right)$ and extension $\left(72^{\circ} \mathrm{C}, 1.5 \mathrm{~min}\right)$, with a final extension step $\left(72^{\circ} \mathrm{C}, 8 \mathrm{~min}\right)$. The amplified DNA was separated by submarine gel electrophoresis on $1.5 \%$ agarose, stained with ethidium bromide and visualized under UV trans illumination.

\section{RESULTS AND DISCUSSION}

The $V$. parahaemolyticus is an enteric human pathogen that occurs naturally in the marine and estuarine environments worldwide. Several outbreaks of seafood poisoning were caused by $V$. parahaemolyticus in many countries and regions of the world including USA, Japan, India and Taiwan [10]. In this study, a total of 70 individual wild shrimp samples were studied for the presence of pathogenic $V$. parahaemolyticus. A conventional cultural method based on the appearance of green or blue- green colonies on TCBS agar and microscopic examination was detected presumptive $V$. parahaemolyticus in $30(42.8 \%)$ out of the 70 shrimp samples. However, the biochemical tests of the presumptive $V$. parahaemolyticus strains indicated that $22.8 \%(16 / 70)$ of shrimp samples were positive for $V$. parahaemolyticus. Variable incidences of $V$. parahaemolyticus in seafood had been demonstrated using conventional methods. The frequency of $V$. parahaemolyticus in our study was lower than some previous studies. According to Abd-Elghany \& Sallam [10] and Quintoil et al [17], the frequency of $V$. parahaemolyticus in shellfish samples was $33.3 \%$, and $36.8 \%$, respectively. However, lower incidence of $V$. parahaemolyticus in seafood samples was reported from Italy and Netherlands with $6.2 \%, 24.3 \%$ and $8 \%$, respectively $[1,18,19]$.

This variation in $V$. parahaemolyticus frequency among seafood samples may be due to the difference of the geographical region, type of shellfish sample, watersalinity, seasons of sampling, post-harvest practices and hygienic standards applied during the handling, transport and storage of seafood products, as well as the methods used for isolation and identification of the organism [10].

Fast and accurate diagnosis of food-borne pathogens is very important for a positive outcome of eradication programs. PCR based methods which target the conserved region of $V$. parahaemolyticus such as toxR gene is more efficient, reliable and faster compare to the conventional techniques [20]. In our study, the biochemically identified isolates were further verified using PCR targeting the $v p$-toxR gene. It has been indicated that 12 (17.1\%) samples out of a total 70 shrimp samples were positive for $v p$-tox $R$ gene. In the present study, the frequency of $V$. parahaemolyticus positive samples based on $v p-t o x R$ gene, was approximately similar to those reported by Abd-Elghany \& Sallam in Egypt [10], who found that $16.7 \%$ of shellfish samples were positive for $v p$-toxR gene and also by Hassan et al. [18] in the Netherlands, who detected that 19\% (38/200) of retailed shellfish samples were positive for toxR gene. Only a few reports on the frequency of $V$. parahaemolyticus in seafood samples from Iran have been previously published. According to the previous reports from Iran, $9.3 \%$ and $11 \%$ of the shrimp samples $[13,21]$ and $21.4 \%$ of the fish samples [22] were positive for the presence of this pathogen.

As the presence of $V$. Parahaemolyticus strains carrying $t d h$ and/or $t r h$ genes in seafood represents a public health risk, their detection would be of paramount importance. It is well known that only $1-2 \%$ of the environmental strains 
possess the $t d h$ gene. Of the 70 shrimp samples in our study, only $2(2.8 \%) t d h$ and $1(1.4 \%) t r h$ positive strains were identified. In the previous report from Iran, the prevalence of $t d h$-positive and $t r h$-positive $V$. parahaemolyticus was $1.7 \%$ and $0.7 \%$, respectively [21]. Similar to our results, in a study conducted in Malaysia, $5(3.9 \%)$ and $1(0.78 \%)$ strains isolated from live and frozen shrimp, respectively were positive for $t$ dh gene, whilst $2(1.56 \%)$ and $1(0.78 \%)$ strains were positive for trh gene [23]. However, higher incidence of virulence $V$. parahaemolyticus was identified in several studies such as the study conducted in Turkey by Terzi et al. [24] who found that 24 (75\%) out of the 32 strains isolated from mussel were potentially pathogenic depending on $t d h$ and $t r h$ genes.

\section{CONCLUSION}

In conclusion, the detection of $t d h$ and/or trh positive $V$. parahaemolyticus in shrimp marketed in Zanjan, Iran shows a probable risk for public health. Therefore, intensive and continuous monitoring of potentially pathogenic $V$. parahaemolyticus are strongly recommended in order to evaluate the human health risk arising from seafood consumption.

\section{ETHICS APPROVAL AND CONSENT TO PARTICIPATE}

Not applicable.

\section{HUMAN AND ANIMAL RIGHTS}

No Animals/Humans were used for studies that are base of this research.

\section{CONSENT FOR PUBLICATION}

Not applicable.

\section{CONFLICT OF INTEREST}

The authors declare no conflict of interest, financial or otherwise.

\section{ACKNOWLEDGEMENTS}

This investigation was supported by Student Research Center, Zanjan University of Medical Sciences, Zanjan, Iran (A-12-392-10, ZUMS.REC.1393.265).

\section{REFERENCES}

[1] Di Pinto A, Ciccarese G, De Corato R, et al. Detection of pathogenic Vibrio parahaemolyticus in southern Italian shellfish. Food Control 2008; 19: 1037-41. [http://dx.doi.org/10.1016/j.foodcont.2007.10.013]

[2] Fujino T, Okuno Y, Nakada D, et al. On the bacteriological examination of shirasu food poisoning. Med J Osaka Univ 1953; 4: 299-304.

[3] Drake SL, DePaola A, Jaykus LA. An overview of Vibrio vulnificus and Vibrio parahaemolyticus. Compr Rev Food Sci Food Saf 2007; 6: $120-44$.

[http://dx.doi.org/10.1111/j.1541-4337.2007.00022.x]

[4] Gopal S, Otta SK, Kumar S, Karunasagar I, Nishibuchi M, Karunasagar I. The occurrence of Vibrio species in tropical shrimp culture environments; implications for food safety. Int J Food Microbiol 2005; 102(2): 151-9. [http://dx.doi.org/10.1016/j.ijfoodmicro.2004.12.011] [PMID: 15992615]

[5] Wang JJ, Sun WS, Jin MT, et al. Fate of Vibrio parahaemolyticus on shrimp after acidic electrolyzed water treatment. Int J Food Microbiol 2014; 179: 50-6.

[http://dx.doi.org/10.1016/j.ijfoodmicro.2014.03.016] [PMID: 24727382]

[6] Chowdhury NR, Chakraborty S, Ramamurthy T, et al. Molecular evidence of clonal Vibrio parahaemolyticus pandemic strains. Emerg Infect Dis 2000; 6(6): 631-6. [http://dx.doi.org/10.3201/eid0606.000612] [PMID: 11076722]

[7] Su Y-C, Liu C. Vibrio parahaemolyticus: A concern of seafood safety. Food Microbiol 2007; 24(6): $549-58$. [http://dx.doi.org/10.1016/j.fm.2007.01.005] [PMID: 17418305]

[8] Hosseini H, Cheraghali AM, Yalfani R, et al. Incidence of Vibrio Spp. in shrimp caught off the south coast of Iran. Food Control 2007; 15: 187-90. [http://dx.doi.org/10.1016/S0956-7135(03)00045-8]

[9] Fuenzalida L, Armijo L, Zabala B, et al. Vibrio parahaemolyticus strains isolated during investigation of the summer 2006 seafood related diarrhea outbreaks in two regions of Chile. Int J Food Microbiol 2007; 117(3): 270-5. 
[http://dx.doi.org/10.1016/j.ijfoodmicro.2007.03.011] [PMID: 17521760]

[10] Abd Elghany SM, Sallam KI. Occurrence and molecular identification of Vibrio parahaemolyticus in retail shellfish in Mansoura, Egypt. Food Control 2013; 33: 399-405.

[http://dx.doi.org/10.1016/j.foodcont.2013.03.024]

[11] Rahimi E, Tajbaksh E, Fadaeifard F, et al. Prevalence of Vibrio Spp. in marine shrimp (Paeneus monodon) caught off the persian gulf coast of Iran. Iranian J Food Sci Technol 2001; 21-6.

[12] Suffredini E, Mioni R, Mazzette R, et al. Detection and quantification of Vibrio parahaemolyticus in shellfish from Italian production areas. Int J Food Microbiol 2014; 184: 14-20.

[http://dx.doi.org/10.1016/j.ijfoodmicro.2014.04.016] [PMID: 24810197]

[13] Zarei M, Borujeni MP, Jamnejad A, et al. Seasonal prevalence of vibrio species in retail shrimps with an emphasis on Vibrio Parahaemolyticus. Food Cont 2012; 25: 107-9. [http://dx.doi.org/10.1016/j.foodcont.2011.10.024]

[14] Robert-Pillot A, Copin S, Gay M, Malle P, Quilici ML. Total and pathogenic Vibrio parahaemolyticus in shrimp: Fast and reliable quantification by real-time PCR. Int J Food Microbiol 2010; 143(3): 190-7. [http://dx.doi.org/10.1016/j.ijfoodmicro.2010.08.016] [PMID: 20843573]

[15] Raghunath P, Acharya S, Bhanumathi A, Karunasagar I, Karunasagar I. Detection and molecular characterization of Vibrio parahaemolyticus isolated from seafood harvested along the southwest coast of India. Food Microbiol 2008; 25(6): 824-30. [http://dx.doi.org/10.1016/j.fm.2008.04.002] [PMID: 18620975]

[16] Kim YB, Okuda J, Matsumoto C, Takahashi N, Hashimoto S, Nishibuchi M. Identification of Vibrio parahaemolyticus strains at the species level by PCR targeted to the toxR gene. J Clin Microbiol 1999; 37(4): 1173-7. [PMID: 10074546]

[17] Quintoil NM, Porteen K, Pramanik AK. Studies on occurrence of Vibrio parahaemolyticus in fin fishes and shellfishes from different ecosystem of West Bengal. Livest Res Rural Dev 2007; 19: 215-9.

[18] Hassan ZH, Zwart kruis Nahuis JT, de Boer E. Occurrence of Vibrio parahaemolyticus in retailed seafood in The Netherlands. International Food Research Journal 2012. 19: 39e43

[19] Ottaviani D, Santarelli S, Bacchiocchi S, et al. Presence of pathogenic Vibrio parahaemolyticus strains in mussels fromthe Adriatic Sea, Italy. Food Microbiol 2005. 22: 585e590.

[20] Khan JA, Rathore RS, Khan S, Ahmad I. In vitro detection of pathogenic Listeria monocytogenes from food sources by conventional, molecular and cell culture method. Braz J Microbiol 2014; 44(3): 751-8. [http://dx.doi.org/10.1590/S1517-83822013000300013] [PMID: 24516442]

[21] Rahimi E, Ameri M, Doosti A, Gholampour AR. Occurrence of toxigenic Vibrio parahaemolyticus strains in shrimp in Iran. Foodborne Pathog Dis 2010; 7(9): 1107-11. [http://dx.doi.org/10.1089/fpd.2010.0554] [PMID: 20528175]

[22] Basti AA, Misaghi A, Salehi TZ, et al. Bacterial pathogens in fresh, smoked and salted Iranian fish. Food Control 2006; 17: 183-8. [http://dx.doi.org/10.1016/j.foodcont.2004.10.001]

[23] Sujeewa AK, Norrakiah AS, Laina M. Prevalence of toxic genes of Vibrio parahaemolyticus in shrimps (Penaeus monodon) and culture environment. Int Food Res J 2009. 16: 89e95.

[24] Terzi G, Büyüktanir O, Yurdusev N. Detection of the tdh and trh genes in Vibrio parahaemolyticus isolates in fish and mussels from middle black seacoast of Turkey. Let Appl Microbiol 2009; 49: 757e -63.

(C) 2018 Asgarpoor et al.

This is an open access article distributed under the terms of the Creative Commons Attribution 4.0 International Public License (CC-BY 4.0), a copy of which is available at: (https://creativecommons.org/licenses/by/4.0/legalcode). This license permits unrestricted use, distribution, and reproduction in any medium, provided the original author and source are credited. 